\title{
Doc'Apella: A Vocal Performance Group Designed to Reduce Stress And Prevent Burnout Among Medical and Health Sciences Students
}

\author{
Kristy J. Carlson, PhD' ${ }^{1}$, Laura E. Newton, MD², Paul J. Brosnihan, MD³ ${ }^{3}$ Steven P. Wengel, MD'1, Jayme R. Dowdall, MD'
}

\begin{abstract}
Introduction: Burnout is common among health professions trainees characterized by emotional exhaustion induced by repeated stressors. Although traditional stress management activities to promote wellness are effective in reducing stress short-term, alternative approaches are needed with the potential for long-term impact. To address burnout among students at the University of Nebraska Medical Center (UNMC), a vocal group was formed to provide a creative outlet. The purpose of this study was to determine the students' motivation for joining Doc'Apella and assess the impact on burnout.
\end{abstract}

Methods: Students enrolled in a health sciences program were invited to participate during the 2018-19 academic year (August-May). Two volunteer students arranged the music, recorded individual practice tracks, and directed the group during rehearsals two nights/week from 5:30-6:30. Group members selected arrangements and performed in a variety of settings. At the end of the year, participants were invited to complete an anonymous online survey.

Results: Of the 98 students on the roster, 18 (18.4\%) responded to the survey. Participants included medical students $(n=9,50.0 \%)$, three graduate students $(16.7 \%)$, two public health students $(11.1 \%)$, one pharmacy student (5.5\%), and three classified as "other" (16.7\%). Nine (50.0\%) indicated the aspect of the group that was MOST important was "escaping my stress or frustration with a creative activity." Thirteen $(72.2 \%)$ felt Doc'Apella was very or extremely beneficial to their "own sense of wellbeing" and 94.4\% $(n=17)$ reported Doc'Apella "helped reduce stress and burnout" somewhat or very much.

Conclusion: Creating music with others may provide an effective way for medical trainees to not only to express creative energy but also to connect with others across health professions. Although the results support structured creative activities to reduce stress and burnout, a large-scale study is needed will strengthen empirical evidence and highlight the impact for health professions trainees.

\author{
DOI: 10.18297/jwellness/vol2/iss2/5 \\ Received Date: June 25, 2020 \\ Accepted Date: Aug 28, 2020 \\ Publication Date: Sept 21, 2020 \\ Website: $\underline{\text { https://ir.library.louisville.edu/ }}$ \\ jwellness/ \\ Recommended Citation: Carlson, Kristy \\ J.; Newton, Laura E.; Brosnihan, Paul J.; \\ Wengel, Steven P.; Dowdall, Jayme R. (2020) \\ "Doc'Apella: A Vocal Performance Group \\ Designed to Reduce Stress And Prevent \\ Burnout Among Medical and Health \\ Sciences" Journal of Wellness: Vol. 2 : Iss. \\ 2, Article 5 . \\ Affiliations: 'University of Nebraska Medical \\ Center, ${ }^{2}$ Dartmouth College, ${ }^{3}$ Vanderbilt \\ University
}

\section{INTRODUCTION}

Burnout is common among medical students [1,2] and tends to strengthen as physicians graduate and progress into residency training $[3,4]$. The cardinal symptoms of burnout are emotional exhaustion, depersonalization, and impaired sense of personal accomplishment induced by repeated stressors and may develop during undergraduate medical school training [5]. This phenomenon has been widely reported and linked to high rates of depression among physicians [6], deteriorating job performance and a loss of empathy for patients [5]. Although traditional stress management activities (i.e., meditation, journaling) to promote wellness among medical trainees are effective in reducing stress, Ziegelstein and colleagues suggest medical schools and residency programs address burnout by facilitating social engagement through structured opportunities to establish meaningful connections [7]. This was reinforced in a publication by chief medical residents recommending a shift in focus "from addressing burnout to fostering meaning within residency" [8]. Further, an inverse relationship was reported in a recent study between engagement and burnout/perceived stress among medical students [9].

One approach to engaging trainees and cultivating meaning may be through formal support of creative outlets and hobbies $[10,11]$. Musical expression, such as singing, is one

${ }^{*}$ Correspondence To: Kristy Carlson

Email: kristy.carlson@unmc.edu option to establish connections, build resilience, and decrease burnout. A multi-institutional study of U.S. medical students revealed that exposure to literature, music, theater, and visual arts reduces symptoms of burnout in medical students and increases empathy, resilience, and tolerance of ambiguity [12]. The therapeutic and anxiolytic impact of the humanities may be driven by physiological changes. There is evidence that music engages the neurochemical systems for reward, motivation, pleasure, stress, immunity, and social affiliation [13]. For example, studies show that serum concentrations of both salivary IgA, a marker of immune function, and oxytocin, a hormone involved in human connection, increase after singing lessons $[14,15]$. Several studies also report decreases in cortisol, a hormone integral to the stress response, for subjects during the act of singing and other creative activities [13, 14, 16-20]. Group singing in particular has also been shown to reduce stress and arousal, measured by serum levels of ACTH, a precursor to cortisol [21].

To address burnout among health sciences students, the University of Nebraska Medical Center (UNMC) created Doc'Apella, a volunteer student vocal performance group designed to provide a creative outlet through music. The purpose of this study was to assess the students' motivation for joining Doc'Apella and the impact on student burnout.

Copyright: @ 2020 The author(s). This is an open access article distributed under the terms of the Creative Commons Attribution 4.0 International License (CC BY 4.0), which permit dhe original author 1 and source are credited. 


\section{METHODS}

\section{Group Organization}

Doc'Apella members were recruited via emails to students, word-of-mouth, and a table at an orientation fair. Group rehearsals were scheduled two nights per week from 5:30-6:30pm. Two volunteer students arranged the music, recorded practice tracks, managed a shared drive, and directed the group. Members selected arrangements from a variety of genres including current pop, oldies, folk songs, and holiday music. Students performed in groups of 4-20 in a variety of settings, including inpatient hospital floors and visitor waiting rooms, medical student meetings, the UNMC Engage Wellness senior exercise program, the Nebraska Hospital Association Caring Kind Luncheon, the UNMC Well-Being Symposium, the annual pediatric holiday party, and the Anatomic Donor Ceremony.

\section{Participants}

Students enrolled in a health sciences program were invited to participate in Doc'Apella during the 2018-2019 academic (August-May) year. Members of the group were invited to participate in the study via email and at rehearsal. The research team did not anticipate a response adequate to analyze paired responses from a pre-survey in August and post-survey in May, so data collection was completed at the end of the program. Participation was voluntary and approved by the UNMC Institutional Review Board (\#586-19-EX).

\section{Study Procedures}

At the end of the academic year, participants were invited to complete an online survey via email. Participant responses were anonymous. The survey was adapted from a similar study of participant involvement in the UNMC orchestra. The survey consisted of questions prompting students to rate their current and past states of wellness (i.e. before and after joining Doc'Apella) and to assess the benefits of participating in Doc'Apella. Responses to four open-ended questions were added to the end of the survey to collect qualitative data. A burnout question was derived from the Mini $\mathrm{Z}$ survey of physician burnout [22]. The complete survey is available as Supplemental Digital Appendix 1. The analysis included descriptive statistics using IBM SPSS Statistics for Windows (IBM Corp. Released 2017. IBM SPSS Statistics for Windows, Version 25.0. Armonk, NY: IBM Corp).

\section{RESULTS}

\section{Doc'Apella Participants}

A total of 98 individuals participated in the group at least once. Members of the group attending on a regular basis (at least $1 / 2$ of the rehearsals) were 12 males (50.0\%) and 12 females $(50.0 \%)$. Thirteen were medical students (54.2\%), four were nursing students (16.6\%), four were graduate students $(16.7 \%)$, and three were public health students $(12.5 \%)$. The typical attendance at rehearsals was $10-15$ and $14-16$ vocalists participated in performances.

\section{Survey Participants}

Of the 98 students on the Doc'Apella roster, 18 (18.4\%) responded to the survey. Study participants were medical students $(n=9,50.0 \%)$, three graduate students $(16.7 \%)$, two public health students $(11.1 \%)$, one pharmacy student $(5.5 \%)$ and three classified as "other" (16.7\%).

\section{Participation and Importance}

Respondents were asked why they originally joined Doc'Apella and the reasons participation was important to them. Results are displayed in Table 1. Doc'Apella participants were also asked to indicate which aspect was MOST important to them? "Escaping my stress or frustration with a creative activity" was the most frequent answer $(n=9 ; 50.0 \%)$. This was followed by "building new community and/or friendships" ( $\mathrm{n}=4 ; 22.2 \%)$, "stimulating my mind and/or developing my skills outside of my profession" $(n=3 ; 16.7 \%)$, and "performing music for myself" $(\mathrm{n}=2 ; 11.1 \%)$.

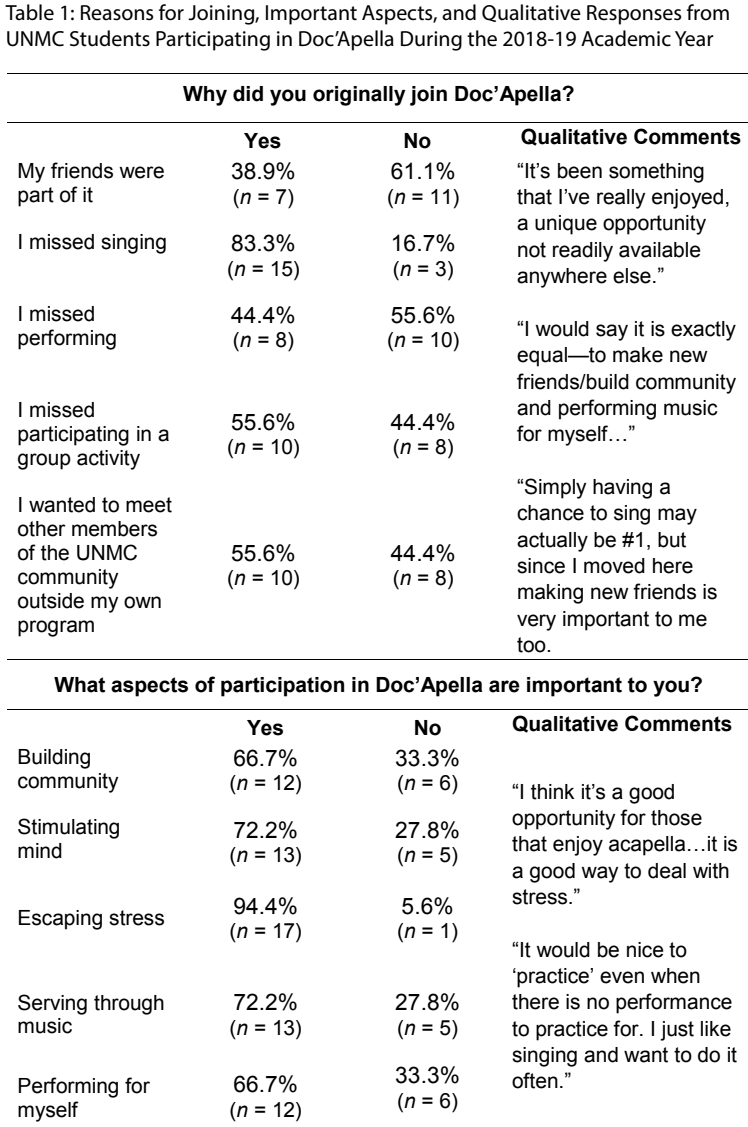

\section{Symptoms of Burnout}

Participants were asked to respond to questions regarding their symptoms of burnout prior to joining Doc'Apella and burnout symptoms they were currently experiencing. Results are displayed in Table 2 (next page). Although overall rates of burnout appeared to decrease among the survey respondents, there were some in the group who still felt symptoms that had a negative impact on their life. Responses also indicated thirteen $(72.2 \%)$ of the participants felt Doc'Apella was very or extremely beneficial "on your own sense of wellbeing." Participants also felt participation in Doc'Apella "has helped reduce stress and burnout in your life" somewhat $(n=9 ; 50.0 \%)$ or very much $(\mathrm{n}=8 ; 44.4 \%)$.

\section{DISCUSSION}

Music's beneficial impact on mood, mental health, and overall wellbeing are consistently documented in the literature $[23,24]$. For health professionals - a population that faces heavy workloads and elevated rates of depression, anxiety, suicide, and burnout-music represents an opportunity for addressing these issues and building resilience. This study supports use of singing groups as a tool for medical students and other health professions students to combat burnout, as almost all respondents felt singing as a group helped them escape stress and frustration. 
Table 2: Burnout Symptoms Before Joining Doc'Apella and Today

\begin{tabular}{|c|c|c|c|c|c|}
\hline \multicolumn{6}{|c|}{ Thinking back to the time before Doc'Apella* } \\
\hline $\begin{array}{l}\text { I enjoyed my work / } \\
\text { studies. I felt no } \\
\text { symptoms of burnout. }\end{array}$ & $\begin{array}{l}\text { I was under stress, but I } \\
\text { didn't feel burned out. }\end{array}$ & $\begin{array}{l}\text { I was definitely burning out and } \\
\text { felt one or more symptoms of } \\
\text { burnout. }\end{array}$ & $\begin{array}{l}\text { I experienced symptoms of } \\
\text { burnout that wouldn't go away. I } \\
\text { thought a lot about work / } \\
\text { academic frustrations. }\end{array}$ & $\begin{array}{c}\text { I felt extremely burned out, } \\
\text { to the point where I } \\
\text { considered seeking or did } \\
\text { seek help. }\end{array}$ & Total Responses \\
\hline $100 \%,(n=0)$ & $50 \%,(n=9)$ & $16.7 \%,(n=3)$ & $22.2 \%,(n=4)$ & $11.1 \%,(n=2)$ & $100 \%,(n=18)$ \\
\hline \multicolumn{6}{|c|}{ After Doc'Apella* } \\
\hline $\begin{array}{l}\text { I enjoy my work / studies. } \\
\text { I feel no symptoms of } \\
\text { burnout. }\end{array}$ & $\begin{array}{l}\text { I am under stress, but I } \\
\text { don't feel burned out. }\end{array}$ & $\begin{array}{l}\text { I am definitely burning out and } \\
\text { feel one or more symptoms of } \\
\text { burnout. }\end{array}$ & $\begin{array}{c}\text { I experience symptoms of } \\
\text { burnout that won't go away. I } \\
\text { think a lot about work / academic } \\
\text { frustrations. }\end{array}$ & $\begin{array}{c}\text { I feel extremely burned } \\
\text { out, to the point where I } \\
\text { considered seeking or did } \\
\text { seek help. }\end{array}$ & \\
\hline $5.6 \%,(n=1)$ & $61.1 \%,(n=11)$ & $5.6 \%,(n=1)$ & $22.2 \%,(n=4)$ & $5.6 \%,(n=1)$ & $100 \%,(n=18)$ \\
\hline \multicolumn{6}{|c|}{ How beneficial has your participation in Doc'Apella been on your own sense of wellbeing? } \\
\hline Not At All & Minimally & Somewhat & Very & Extremely & \\
\hline $0.00 \%(n=0)$ & $5.60 \%(n=1)$ & $22.20 \%(n=4)$ & $38.90 \%(n=7)$ & $33.30 \%(n=6)$ & $100.00 \%(n=18)$ \\
\hline \multicolumn{6}{|c|}{ To what extent do you believe that your participation in Doc'Apella has helped reduce stress and burnout in your life? } \\
\hline Not At All & Minimally & Somewhat & Very & Extremely & \\
\hline $0.00 \%(n=0)$ & $5.60 \%(n=1)$ & $50.00 \%(n=9)$ & $44.40 \%(n=8)$ & $0.00 \%(n=0)$ & $100.00 \%(n=18)$ \\
\hline
\end{tabular}

*Respondents were asked to select which description of burnout most closely described them, using their own definition of burnout. Participants responded by choosing one option before the Doc'Apella intervention and one option after. Both responses were collected at the same time following the intervention. The analysis was completed with group responses and not paired data due to subject anonymity.

Creating music with others may provide an effective way for students not only to express creative energy but also to connect with one another. Group singing has been shown to promote feelings of inclusion and connectivity and to form social bonds quickly, perhaps through its unique combination of support, camaraderie, and self-expression [25-27]. Coordinating breaths, synchronizing the placement of consonants, and listening carefully in order to harmonize in tune and match dynamics requires a level of cooperation that dissolves boundaries between the self and others. The reciprocal interactions inherent to group singing foster a sense of shared goals and meaningful belonging $[24,28]$. The interdisciplinary nature of Doc'Apella emphasizes the potential of group singing to enhance communication and promote a collaborative culture both within and across health professions [25]. Over half $(55.6 \%)$ of the survey respondents indicated they joined the group to meet others in the UNMC community outside their academic program. In addition, two-thirds (66.7\%) reported building community was an important aspect of the group.

Medical schools, residency programs, and hospitals in the United States have become increasingly aware in recent years of the issues burnout can create in their environments, both for students and for the broader health care community [5, $9,29]$. From increased rates of depression and suicidal ideation to poor performance and worse patient-care outcomes, burnout cultivates a negative work culture that undermines the incredible work health professionals do every day [5, $9,29]$. The stress and rigor inherent in medical school and other health professional education across the country can often become maladaptive and even harmful. At the time of this survey, $50 \%$ of student respondents reported experiencing various levels of burnout, from "extremely burned out" to "definitely burning out and felt one or more symptoms of burnout." This tracks with the report from American Academy of Family Physicians (AAFP) that nationally 50\% of medical students will experience burnout at some point during their medical school career [30]. Two students in this survey endorsed "severe burnout to the point of seeking help," which further correlated with AAFP's research showing that $10 \%$ of residents experience severe burnout involving depressive symptoms and suicidal ideation [30]. As medical students prepare for the elevated responsibilities and stress brought by residency, preparing them mentally and emotionally runs tantamount to preparing them academically and clinically. Promoting strong habits of self-care and creative outlets in medical school can help arm students with tools to foster resiliency, which they can continue to employ in residency and, eventually, as part of health care teams across the span of their career.

This study contributes to the myriad research currently underway regarding potential interventions that may mitigate or prevent against burnout by stimulating the creativity, emotions, and empathy of providers and students. Several groups have utilized music as a tool to build resilience and have studied the positive impact that engaging in singing groups can provide. A study by Skingley and Ross formed a nurses singing group to decrease burnout within hospital teams and found that participation in the group not only decreased rates of burnout, but also improved job performance, both in the short term and cumulatively over time [31]. A randomized, controlled study of a recreational music protocol in an interdisciplinary group of long-term care workers found significant reductions in multiple measures of burnout [32].

Music has proved an effective tool against burnout in other high-stress industries outside health care as well. For example, one study showed reduced burnout symptoms in teachers who participated in counseling groups that utilized music therapy when compared to teachers in counseling groups that used cognitive behavioral interventions alone [33]. Many medical schools have already established programs to increase students' exposure to creative endeavors during their training. Stanford actively encourages students to engage with the arts alongside their coursework, striving to build a community of medical practitioners dedicated to "art-enabled reflective practice" [34]. Similarly, Weill Cornell College of Medicine formed an a cappella group and partners with Juilliard to encourage their students to participate in the arts [35].

Although this was a small single-site study, the benefits identified by Doc'Apella participants may be achieved in similar interventions focused on creative group activities. The nature of this study's design brings inherent limitations. Cause and effect are difficult to ascertain given the potential for confounding factors. Retrospective surveys are also prone the subjective influence of emotional memories and cognitive biases due to their reliance on self-reporting. While the difference between the student's levels of burnout before versus after participation was not significant in our study, this parameter would be better elucidated by asking these questions on separate surveys prior to participation and immediately after participation. Future studies could improve upon this design by collecting paired data that links each subject's before and after scores. In addition, the small sample size limits the study's power. Lastly, since members of this singing group 
represent diverse health education programs, future studies could further characterize how level of burnout and potential benefit of singing group participation may vary by health profession.

\section{CONCLUSION}

After several successful performances sharing music with patients and with the community, some Doc'apella members noticed a change in overall wellbeing after rehearsals and exchanged mutual realizations that something had been missing in their lives. As medical trainees, participating in music was a casualty of limited free time. This study supports structured activities involving music as a creative outlet to connect with their health professions community and relieve stress and frustration often felt during medical training. The positive results from this study may be strengthened by assessing the impact of structured creative opportunities (i.e., music, art, writing) on a larger scale.

\section{REFERENCES}

1. Erschens R, Keifenheim KE, Herrmann-Werner A, Loda T, Schwille-Kiuntke J, Bugaj TJ, et al. Professional burnout among medical students: systematic literature review and meta-analysis. Med Teach. 2019 Feb;41(2):172-83.

2. Frajerman A, Morvan Y, Krebs MO, Gorwood P, Chaumette B. Burnout in medical students before residency: A systematic review and meta-analysis. Eur Psychiatry. 2019 Jan;55:36-42.

3. Ripp JA, Privitera MR, West CP, Leiter R, Logio L, Shapiro J, et al. Well-being in graduate medical education: a call for action. Acad Med. 2017 Jul;92(7):914-7.

4. Prentice S, Dorstyn D, Benson J, Elliott T. Burnout Levels and Patterns in Postgraduate Medical Trainees: A Systematic Review and Meta-Analysis. Acad Med. 2020 Sep;95(9):1444-54.

5. Mazurkiewicz R, Korenstein D, Fallar R, Ripp J. The prevalence and correlations of medical student burnout in the pre-clinical years: a cross-sectional study. Psychol Health Med. 2012;17(2):188-95.

6. Connors B, Horne C, Vilchez V, Asfaw S. Physician Burnout. Contemporary Topics in Graduate Medical Education: IntechOpen; 2019. https://doi.org/10.5772/ intechopen.84349.

7. Ziegelstein RC. Creating structured opportunities for social engagement to promote well-being and avoid burnout in medical students and residents. Acad Med. 2018 Apr;93(4):537-9.

8. Berg DD, Divakaran S, Stern RM, Warner LN. Fostering Meaning in Residency to Curb the Epidemic of Resident Burnout: Recommendations From Four Chief Medical Residents. Acad Med. 2019 Nov;94(11):1675-8.

9. Agarwal G, Mosquera M, Ring M, Victorson D. Work engagement in medical students: an exploratory analysis of the relationship between engagement, burnout, perceived stress, lifestyle factors, and medical student attitudes. Med Teach. 2020 Mar;42(3):299-305.

10. Ayala EE, Winseman JS, Johnsen RD, Mason HR. U.S. medical students who engage in self-care report less stress and higher quality of life. BMC Med Educ. 2018 Aug;18(1):189.

11. Ayala EE, Omorodion AM, Nmecha D, Winseman JS, Mason HR. What do medical students do for self-care? A student-centered approach to well-being. Teach Learn Med. 2017 Jul-Sep;29(3):237-46.

12. Mangione S, Chakraborti C, Staltari G, Harrison R, Tunkel AR, Liou KT, et al. Medical students' exposure to the humanities correlates with positive personal qualities and reduced burnout: a multi-institutional US survey. J Gen Intern Med. 2018 May;33(5):628-34.

13. Chanda ML, Levitin DJ. The neurochemistry of music. Trends Cogn Sci. 2013 Apr;17(4):179-93.

14. Kreutz G, Bongard S, Rohrmann S, Hodapp V, Grebe

D. Effects of choir singing or listening on secretory immunoglobulin A, cortisol, and emotional state [Internet]. J Behav Med. 2004 Dec;27(6):623-35. Available from: https://bienetrebleuindigo.com/wp-content/ uploads/2018/09/SINGING-Kreutz2004JBM.pdf

15. Grape C, Sandgren M, Hansson LO, Ericson M, Theorell T. Does singing promote well-being?: an empirical study of professional and amateur singers during a singing lesson [Internet]. Integr Physiol Behav Sci. 2003 Jan-Mar;38(1):65-74. Available from: https://link. springer.com/content/pdf/10.1007/BF02734261.pdf

16. Kaimal G, Ray K, Muniz J. Reduction of cortisol levels and participants' responses following art making. Art Ther (Alex). 2016 Apr;33(2):74-80.

17. Khan SH, Kitsis M, Golovyan D, Wang S, Chlan LL, Boustani M, et al. Effects of music intervention on inflammatory markers in critically ill and post-operative patients: A systematic review of the literature. Heart Lung. 2018 Sep - Oct;47(5):489-96.

18. Koelsch S, Boehlig A, Hohenadel M, Nitsche I, Bauer $\mathrm{K}$, Sack U. The impact of acute stress on hormones and cytokines, and how their recovery is affected by musicevoked positive mood. Sci Rep. 2016 Mar;6(1):23008.

19. Smyth N, Rossi E, Wood C. Effectiveness of stress-relieving strategies in regulating patterns of cortisol secretion and promoting brain health. Int Rev Neurobiol. 2020;150:219-46.

20. Cheever T, Taylor A, Finkelstein R, Edwards E, Thomas L, Bradt J, et al. NIH/Kennedy Center Workshop on Music and the Brain: finding Harmony. Neuron. 2018 Mar;97(6):1214-8.

21. Keeler JR, Roth EA, Neuser BL, Spitsbergen JM, Waters DJ, Vianney JM. The neurochemistry and social flow of singing: bonding and oxytocin. Front Hum Neurosci. 2015 Sep;9:518.

22. Linzer M, Poplau S, Babbott S, Collins T, Guzman-Corrales L, Menk J, et al. Worklife and wellness in academic general internal medicine: results from a national survey. J Gen Intern Med. 2016 Sep;31(9):1004-10.

23. Moss H, Lynch J, O’Donoghue J. Exploring the perceived health benefits of singing in a choir: an international cross-sectional mixed-methods study. Perspect Public Health. 2018 May;138(3):160-8.

24. Thomas L. Can Choir Singing Improve Health?: News Medical Life Sciences. [Internet] 2019 Available from: https://www.news-medical.net/health/Can-ChoirSinging-Improve-Health.aspx

25. Pearce E, Launay J, Dunbar RI. The ice-breaker effect: singing mediates fast social bonding. R Soc Open Sci. 2015 Oct;2(10):150221.

26. Weinstein D, Launay J, Pearce E, Dunbar RI, Stewart L. Singing and social bonding: changes in connectivity and pain threshold as a function of group size. Evol Hum Behav. 2016;37(2):152-8.

27. Clift S, Morrison I. Group singing fosters mental health and wellbeing: findings from the East Kent "singing for health" network project. Mental Health and Social Inclusion; 2011. https://doi. org/10.1108/20428301111140930.

28. Stewart NA, Lonsdale AJ. It's better together: the psychological benefits of singing in a choir. Psychol Music. 2016;44(6):1240-54. 
29. Del Canale S, Louis DZ, Maio V, Wang X, Rossi G, Hojat $\mathrm{M}$, et al. The relationship between physician empathy and disease complications: an empirical study of primary care physicians and their diabetic patients in Parma, Italy. Acad Med. 2012 Sep;87(9):1243-9.

30. Dyrbye LN, Burke SE, Hardeman RR, Herrin J, Wittlin NM, Yeazel M, et al. Association of clinical specialty with symptoms of burnout and career choice regret among US resident physicians. JAMA. 2018 Sep;320(11):1114-30.

31. Skingley A, Ross L. Effects of singing groups on staff well-being: a feasibility study. Nurs Stand. 2018 May;33(3):58-63.

32. Bittman B, Bruhn KT, Stevens C, Westengard J, Umbach PO. Recreational music-making: a cost-effective group interdisciplinary strategy for reducing burnout and improving mood states in long-term care workers
[Internet]. Adv Mind Body Med. 2003;19(3-4):4-15. Available from: https://www.rhythmresearchresources. net/uploads/1/1/2/9/112916705/recreational_ music-making_long_term_care_workers_2.pdf

33. Cheek JR, Bradley LJ, Parr G, Lan W. Using music therapy techniques to treat teacher burnout. J Ment Health Couns. 2003;25(3):204-17.

34. White T. Expressions: Medical students creating art: Standford Medicine [Internet]. 2017. Available from: https://stanmed.stanford.edu/2017winter/ why-stanfords-medical-students-dance-draw-writeplay-music-and-make-films.html

35. Music \& Medicine: Collaboration: Weill Cornell Medicine [Internet]. 2020. Available from: https://music. weill.cornell.edu/collaboration

O UNMC Student, College of Medicine

O UNMC Student, College of Pharmacy

O UNMC Student, College of Public Health

O UNMC Student, College of Graduate Studies

O UNMC Student, Other

Thinking back to the time before you joined Doc'Apella and using your own definition of "burnout," which statement best describes your experience?

I enjoyed/enjoy my work/studies. I felt/feel no symptoms of burnout.

O I was/am under stress, but I didn't/don't feel burned out.

I was/am definitely burning out and felt/feel one or more symptoms of burnout.

O I experienced/experience symptoms of burnout that wouldn't/won't go away. I thought/think a lot about work/academic frustrations.

I felt/feel extremely burned out, to the point where I considered seeking or did seek help.

Why did you originally join Doc'Apella? (check all that apply)

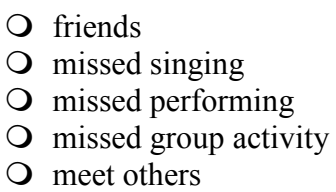

How beneficial has your participation in Doc'Apella been on your own sense of wellbeing?
Not at all beneficial
O Minimally beneficial
Somewhat beneficial
Very beneficial
Extremely beneficial 
To what extent do you believe that your participation in Doc'Apella has helped reduce stress and burnout in your life?

O Not at all

O Minimally

Somewhat

O Very

Extremely

What aspects of participation in Doc'Apella are important to you? (check all that apply)

Escaping my stress or frustration with a creative activity

Building new community and/or friendships

Stimulating my mind and/or developing my skills outside of my profession

Performing music for myself

O Something else

How would you rate the amount of Doc'Apella performances this past year (4 total)?

Too few

Just right

Too many

How would you rate the amount of group practice opportunities this past year?

Too few

Just right

Too many

How important is performing in this type of event?

Least important Somewhat important Most important

UNMC private events

$\begin{array}{llll}0 & 0 & 0\end{array}$

Patient rooms

Broader community

UNMC lobbies

Thinking about today and using your own definition of "burnout," which statement best describes your experience?

O I enjoyed/enjoy my work/studies. I felt/feel no symptoms of burnout.

O I was/am under stress, but I didn't/don't feel burned out.

O I was/am definitely burning out and felt/feel one or more symptoms of burnout.

I experienced/experience symptoms of burnout that wouldn't/won't go away. I thought/think a lot about work/academic frustrations.

O I felt/feel extremely burned out, to the point where I considered seeking or did seek help.

How would you describe burnout?

How would you describe resiliency?

Describe any previous music experience before Doc'Apella.

Please provide any additional comments or suggestions you wish to share about Doc'Apella. 